\title{
Hinweise zum formalen Aufbau und zur Benutzung
}

Das Buch besteht aus Teilen ([0], [1], [2], ...), diese aus Kapiteln ([1.1], [2.3], ...), die wiederum (in der Regel) in Abschnitte ([1.1.1], [2.3.2], ...) untergliedert sind.

Formeln werden innerhalb eines Kapitels (z. B. [4.1]) durchnumeriert ((1), (2), ...), an anderen Stellen wird auf sie in der Form (4.1-1), (4.1-2), ... Bezug genommen. Analoges gilt für die Anhänge [A 1], [A 2], ... mit ihren Formeln (A 3-1), (A 7-2) usw.

Abbildungen und Tabellen werden kapitelweise numeriert und entsprechend Abb. 5.1-2, Abb. 9.3-5, Tab. 10.4-2 usw. zitiert.

Am Ende jedes Teils finden sich Literaturhinweise. Im Text wird auf sie in der Form ... Brovman und Holas (74) . . oder . . Singwi u. a. (70) . . oder . . (Wigner u. Huntington (35) ... verwiesen. 